NATIONAL LABORATORY

MANAGED BY UT-BATTELLE

FOR THE DEPARTMENT OF ENERGY

\title{
Survey of Radiation Effects in Titanium Alloys
}

August 28, 2008

Louis K. Mansur

Materials Science \& Technology Division

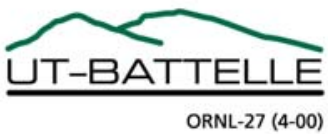




\section{DOCUMENT AVAILABILITY}

Reports produced after January 1, 1996, are generally available free via the U.S. Department of Energy (DOE) Information Bridge.

Web site http://www.osti.gov/bridge

Reports produced before January 1, 1996, may be purchased by members of the public from the following source.

National Technical Information Service

5285 Port Royal Road

Springfield, VA 22161

Telephone 703-605-6000 (1-800-553-6847)

TDD 703-487-4639

Fax 703-605-6900

E-mail info@ntis.gov

Web site http://www.ntis.gov/support/ordernowabout.htm

Reports are available to DOE employees, DOE contractors, Energy Technology Data Exchange (ETDE) representatives, and International Nuclear Information System (INIS) representatives from the following source.

Office of Scientific and Technical Information

P.O. Box 62

Oak Ridge, TN 37831

Telephone 865-576-8401

Fax 865-576-5728

E-mail reports@osti.gov

Web site http://www.osti.gov/contact.html

This report was prepared as an account of work sponsored by an agency of the United States Government. Neither the United States Government nor any agency thereof, nor any of their employees, makes any warranty, express or implied, or assumes any legal liability or responsibility for the accuracy, completeness, or usefulness of any information, apparatus, product, or process disclosed, or represents that its use would not infringe privately owned rights. Reference herein to any specific commercial product, process, or service by trade name, trademark, manufacturer, or otherwise, does not necessarily constitute or imply its endorsement, recommendation, or favoring by the United States Government or any agency thereof. The views and opinions of authors expressed herein do not necessarily state or reflect those of the United States Government or any agency thereof. 
Materials Science \& Technology Division and

Spallation Neutron Source Division

\title{
SURVEY OF RADIATION EFFECTS IN TITANIUM ALLOYS
}

\author{
Louis K. Mansur
}

Date Published: August 29, 2008

\author{
Prepared by \\ OAK RIDGE NATIONAL LABORATORY \\ Oak Ridge, Tennessee 37831-6283 \\ managed by \\ UT-BATTELLE, LLC \\ for the \\ U.S. DEPARTMENT OF ENERGY \\ under contract DE-AC05-00OR22725
}




\title{
Survey of Radiation Effects in Titanium Alloys
}

\author{
L. K. Mansur \\ Materials Science and Technology Division \\ Oak Ridge National Laboratory \\ Oak Ridge, Tennessee 37831-6138 \\ USA
}

\section{$\underline{\text { Abstract }}$}

Information on radiation effects in titanium alloys has been reviewed. Only sparse experimental data from fission reactor and charged particle irradiations is available, none of which is directly applicable to the Spallation Neutron Source (SNS). Within this limited data it is found that although mechanical properties are substantially degraded, several Ti alloys may retain acceptable properties to low or moderate doses. Therefore, it is recommended that titanium alloys be examined further for application to the SNS target. Since information directly relevant to the SNS mercury target environment and irradiation conditions is not available, it is recommended that ORNL generate the necessary experimental data using a graded approach. The first testing would be for cavitation erosion resistance using two different test devices. If the material performs acceptably the next tests should be for long term mercury compatibility testing of the most promising alloys. Irradiation tests to anticipated SNS displacement doses, followed by mechanical property measurements, would be the last stage in determining whether the alloys should be considered for service in the SNS target module.

\section{$\underline{\text { Introduction }}$}

This work is part of an effort to obtain improved structural materials for future spallation targets and upstream proton beam windows, with respect to resistance to cavitation erosion and to radiation effects. In addition, this work is motivated by the fact that if lower density materials could be utilized for the SNS target module and beam windows, then the spallation target would produce a greater yield of neutrons. This higher production results because more of the high energy beam protons would be available to interact with the mercury spallation target rather than being parasitically scattered by the structural material. Titanium alloys have been used extensively in the aerospace and chemical industries because of their high strength to mass ratio, good mechanical properties and their generally high corrosion resistance. In addition, there is extensive experience with fabrication, and the properties databases for non-irradiated properties of several of the alloys are essentially complete.

\section{$\underline{\text { Background }}$}

Ti-6Al-4V is one of a handful of commercially available titanium alloys. It is a popular choice because it is readily available and has good strength at low to moderate temperatures. It is a so-called $\alpha+\beta$ alloy, meaning that it is a phase mixture consisting of $\alpha$ (hcp crystal structure) and discontinuous $\beta$ (bcc crystal structure) grains. The $\alpha$ phase is predominate, 
typically comprising about 80 to $90 \%$ of the material. The fractional distribution is strongly affected by heat treatment, and heat treatment is a powerful method of manipulating the properties of the alloy over broad ranges. The latter advantage contributes to the popularity of $\alpha+\beta$ alloys, because it allows relatively easy fabrication followed by optimization of properties by heat treatment after fabrication. A wide variety of microstructures can be produced for the same chemical composition, giving a method for tailoring the alloy to particular applications. Examples of other alloys that are of interest include the near- $\alpha$ alloy Ti-6242S (Ti-6Al-2Sn-4Zr-2Mo-0.08Si) and the $\alpha$ alloys Ti-5Al-2.5Sn and Ti-4Al-2V.

The physical density of Ti-6Al-4V is $4.4 \mathrm{~g} / \mathrm{cm}^{3}$. For comparison, type $316 \mathrm{LN}$ stainless steel has a density of $8 \mathrm{~g} / \mathrm{cm}^{3}$. The loss of neutrons caused by loss of beam protons is correspondingly better for the titanium alloy. An additional advantage of titanium alloys is that they are considered to be "reduced activation" materials. For example, approximately 100 years after shutdown of a D-T fueled fusion reactor the residual radioactivity would be reduced by more than 8 orders of magnitude, with the longer term radioactivity dominated by the ${ }^{26} \mathrm{Al}$ isotope [Davis, et al., 1994]. Calculations specific to the spallation target of the SNS would need to be carried out to determine the low activation advantage of titanium alloys for this case.

Titanium alloys were considered as a possible primary structural material for fusion reactors in the late 1970's and early 1980's. They were later eliminated from consideration because of several weaknesses, one of which was the lack of data on their irradiation performance. Other reasons were concerns about hydrogen embrittlement, high tritium retention and the relatively low temperature capabilities of many titanium alloys in comparison with the (then) higher temperature aspirations for fusion reactors. More recently, titanium alloys are again being considered for fusion reactors, now in lower exposure applications such as flexible connectors for the first wall modules in the ITER, where they will receive less than $0.3 \mathrm{dpa}$. [Marmy and Leguey, 2001].

Key questions on titanium alloys and, in particular, Ti-6Al-4V for SNS target application relate to 1.) degradation by irradiation, 2.) cavitation erosion resistance in mercury, and 3.) compatibility with mercury. With respect to compatibility, there has been one $50 \mathrm{~h}$ test of Ti$6 \mathrm{Al}-4 \mathrm{~V}$ at room temperature in a stirred mercury bath [Greene and Finfrock, 2003]. No mass loss of the alloy was detected. No reports of tests of cavitation erosion behavior of Ti-6Al$4 \mathrm{~V}$ in $\mathrm{Hg}$ have been found in the literature ${ }^{1}$. In spite of the fact that this alloy has been the subject of several irradiation studies, there is very little relevant information available on its irradiation behavior. The experimental data that is available from these irradiation studies is summarized below.

\section{$\underline{\text { Radiation Effects in Ti-6Al-4V }}$}

\footnotetext{
${ }^{1}$ In response to the survey and recommendations of the present report, new work has been carried out very recently to examine cavitation erosion behavior in acoustic horn tests of several titanium alloys. The work will be published separately in a forthcoming paper [Pawel and Mansur, 2008].
} 
The work has employed three types of irradiating particles: neutron irradiations in fission reactors, high energy proton irradiations, and lower energy heavy-ion and helium ion irradiations of various types. The neutron irradiations achieved only low doses ( $<1 \mathrm{dpa})$, except for one, which reached about $35 \mathrm{dpa}$. The high energy proton irradiation reached doses of $0.3 \mathrm{dpa}$ at 40 and $350^{\circ} \mathrm{C}$. The various lower energy ion beam experiments were conducted over a wide range of temperatures, from about room temperature to $700{ }^{\circ} \mathrm{C}$.

\section{High energy proton irradiations}

High energy proton irradiations were carried out at the Paul Scherrer Institute (PSI) at the Proton Irradiation Experiment (PIREX) facility on the alloys Ti-6Al-4V and Ti-5Al-2.5Sn [Marmy and Leguey, 2001]. The proton beam energy was $590 \mathrm{MeV}$; temperatures of irradiation were 40,200 and $350^{\circ} \mathrm{C}$, and displacement doses ranged from 0.01 to $0.3 \mathrm{dpa}$. Figure 1 shows the load-deformation curves for tensile tests of both alloys irradiated at 350 ${ }^{\circ} \mathrm{C}$ and tested at room temperature. Figure 2 gives the corresponding uniform and total elongations in the form of histograms.

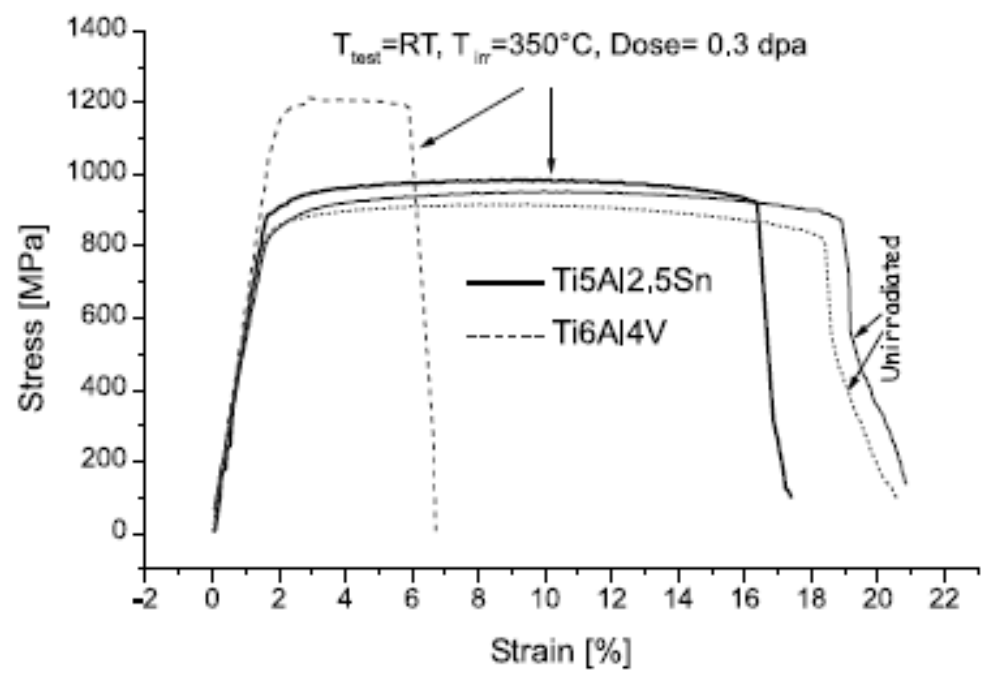

Figure 1. Load deformation curves before and after irradiation for the two titanium alloys irradiated with $590 \mathrm{MeV}$ protons, after [Marmy and Leguey, 2001]. 

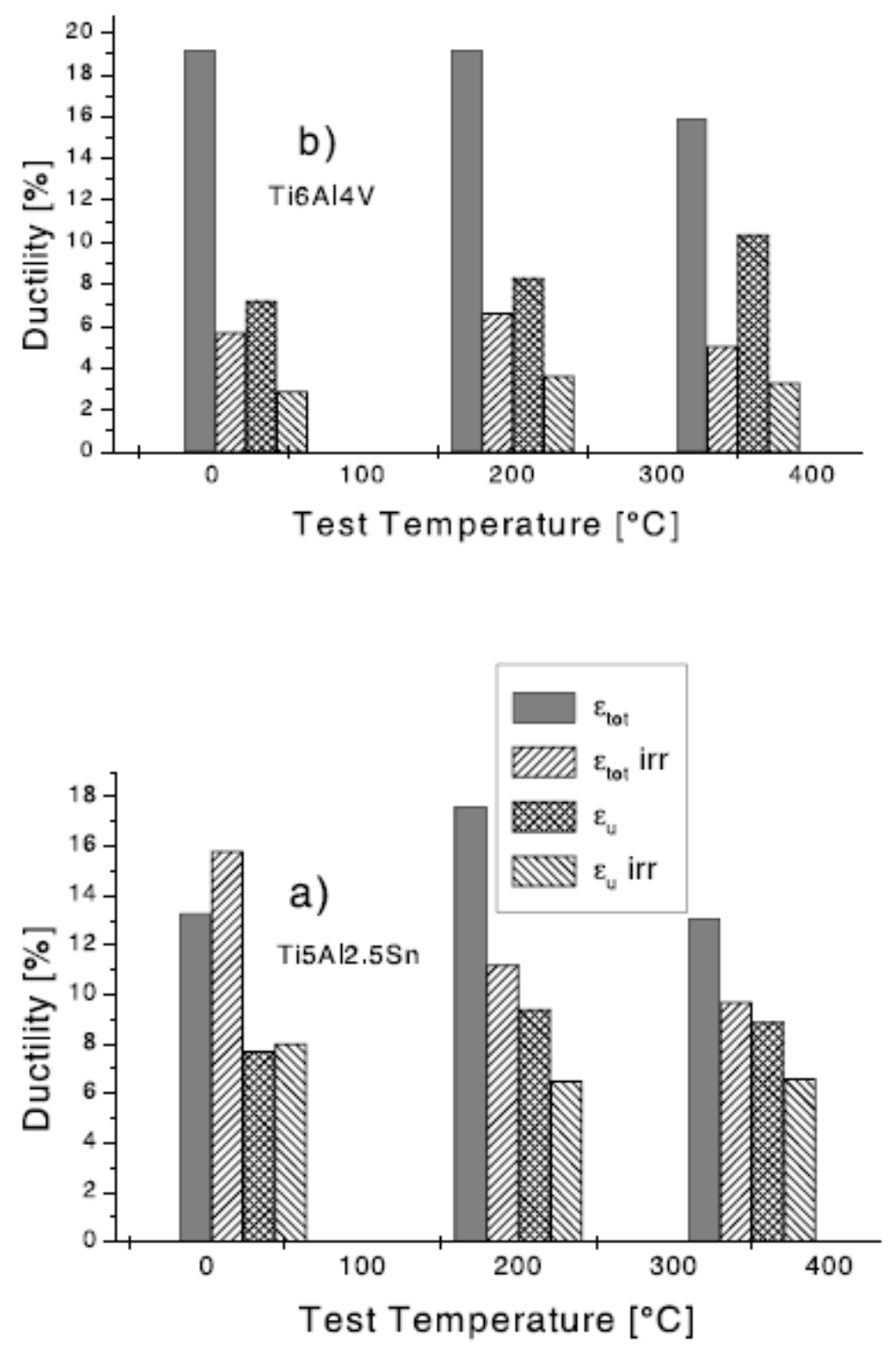

Figure 2. Uniform and total elongation before and after irradiation at $350{ }^{\circ} \mathrm{C}$ and $0.3 \mathrm{dpa}$ as a function of test temperature, after [Marmy and Leguey, 2001]. 
Microstructural observations after irradiation of the Ti-6Al-4V alloy at $350{ }^{\circ} \mathrm{C}$ and tensile testing showed a fine distribution of elongated precipitates of sizes up to $15 \mu \mathrm{m}$ in the alpha phase. Fatigue tests were also carried out. Figure 3 shows the strain controlled deformationcycle curves. For high imposed strains the irradiation reduced the cycle lifetime of the Ti$6 \mathrm{Al}-4 \mathrm{~V}$ alloy. For lower imposed strains there was little difference in the cyclic lifetimes for irradiated and non-irradiated material.
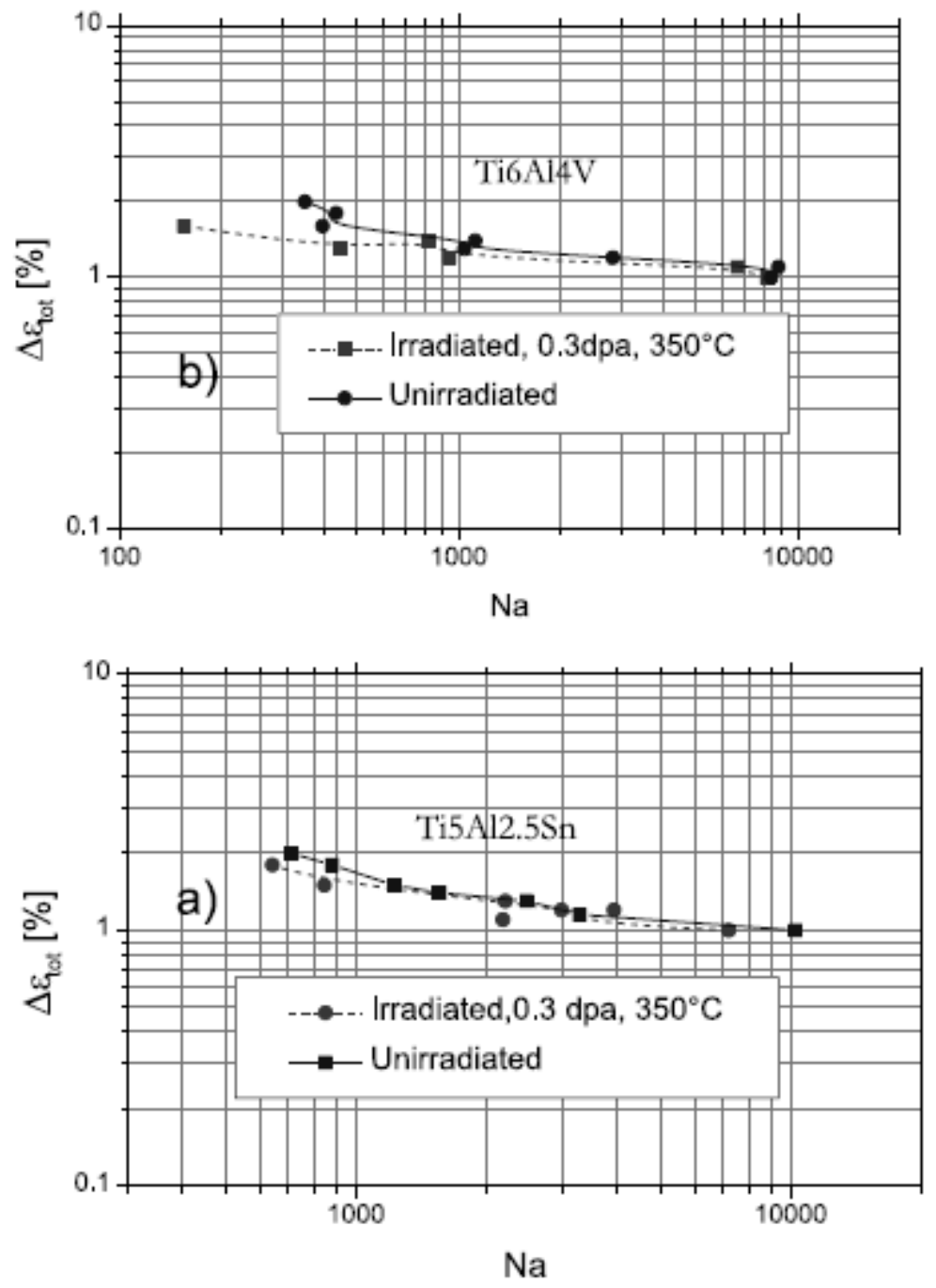

Figure 3. Effect of irradiation on the fatigue life of Ti-6Al-4V and Ti-5Al-2.5Sn, after [Marmy and Leguey, 2001]. 
Microscopic observations of the fracture surfaces showed that they were semi-brittle, but also showed some ductile tearing. Cracking was observed even on non-irradiated material on some fracture surfaces, with the cracks apparently propagating into the material at high angles to the fracture surfaces. This behavior suggests that the inherent anisotropy of the titanium alloys may produce incompatibility stresses between grains. That is, an easy deformation direction in one grain may intersect a difficult deformation direction in an adjacent grain, leading to cracking. These fatigue tests may be relevant to the potential performance of the alloys when subjected to cavitation erosion conditions. One interpretation is that cavitation erosion proceeds by microscopic hammering, fatigue and finally fractures of localized regions leading to pitting.

\section{Low Dose Fission Reactor Irradiations}

There have been several studies of Ti-6Al-4V and other titanium alloys for irradiations to less than 1 dpa [Rodchenkov, et al., 2002; Rodchenkov, et al., in press; Kohyama, et al., 1986]. [Rodchenkov, et al., 2002] irradiated Ti-6Al-4V at 240 to $260{ }^{\circ} \mathrm{C}$ up to a dose of 0.42 dpa in the IVV-2M reactor, and performed mechanical tests at 20 and $260{ }^{\circ} \mathrm{C}$. Figure 4 shows a load displacement curve for non-irradiated and irradiated material.

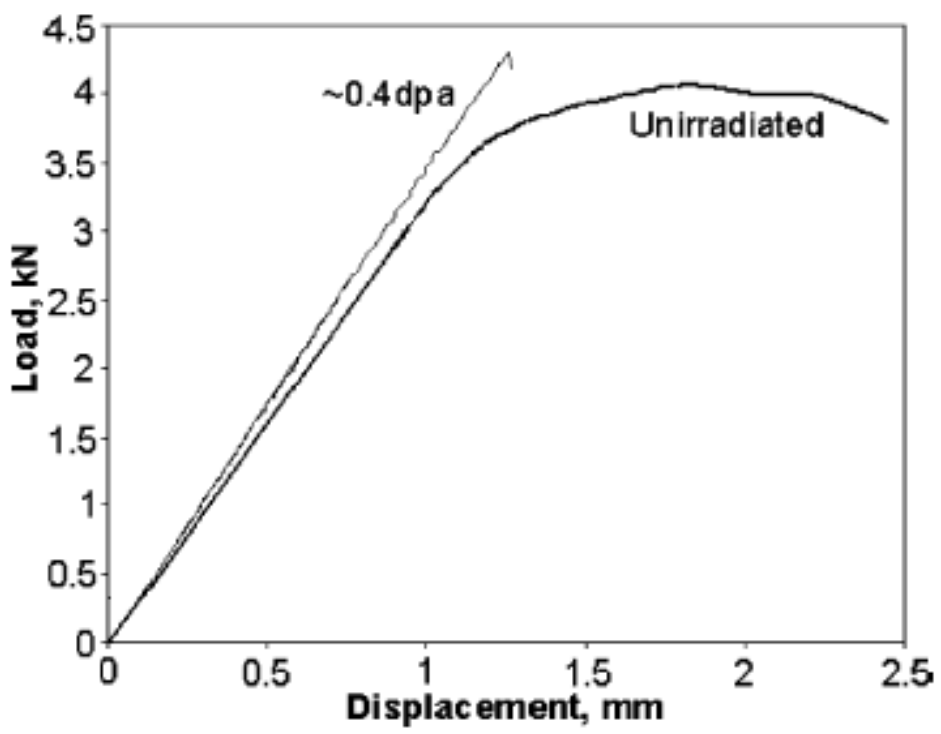

Figure 4. Typical load displacement curve for Ti-6Al-4V at $260{ }^{\circ} \mathrm{C}$, after [Rodchenkov, et al., 2002]. 
Table 1 shows all their reported results of tensile testing of Ti-6Al-4V at 20 and $260{ }^{\circ} \mathrm{C}$.

Table 1. Results of tensile testing of Ti-6Al-4V at 20 and $260^{\circ} \mathrm{C}$, for irradiated and nonirradiated material, after [Rodchenkov, et al., 2002].

\begin{tabular}{lccccccc}
\multicolumn{1}{l}{ Tensile properties of unirradiated and irradiated Ti-6Al-4V alloy } \\
\hline Material & Dose (dpa) & $T_{\text {test }}\left({ }^{\circ} \mathrm{C}\right)$ & UTS $(\mathrm{MPa})$ & YS $(\mathrm{MPa})$ & UEL $(\%)$ & TEL $(\%)$ & RA $(\%)$ \\
\hline Heat 1 & 0 & 20 & 912 & 834 & 6.2 & 13.7 & 39.4 \\
& 0 & 260 & 638 & 510 & 9.0 & 16.6 & 52.0 \\
& $\sim 0.4$ & 20 & 1305 & 1202 & 3.7 & 12.4 & 14.6 \\
Heat $1\left(200 \mathrm{ppm} \mathrm{H}_{2}\right)$ & $\sim 0.4$ & 260 & 1039 & 986 & 2.3 & 4.7 & 15.7 \\
& 0 & 20 & 956 & 842 & 5.7 & 15.6 & 38.7 \\
& 0 & 260 & 653 & 519 & 8.4 & 15.4 & 48.7 \\
Heat 2 & $\sim 0.4$ & 20 & 1325 & 1234 & 5.5 & 13.0 & 15.9 \\
& $\sim 0.4$ & 260 & 1044 & 986 & 2.2 & 5.7 & 15.1 \\
& 0 & 20 & 981 & 791 & 7.3 & 14.5 & 37.4 \\
& 0 & 260 & 662 & 520 & 7.1 & 13.3 & 45.3 \\
& $\sim 0.4$ & 20 & 1327 & 1265 & 6.8 & 12.5 & 15.7 \\
\end{tabular}

Note that there are two heats of the alloy shown. Both heats yielded the $\alpha+\beta$ structure, but the mechanical properties are quite different in irradiated and non-irradiated conditions. Heat 1 was also hydrogenated to examine the effect of "simulated" transmutation produced hydrogen in a fusion reactor. The hydrogen had little effect. Hydrogen effects are also of interest to SNS, where the hydrogen transmutation to dpa ratio can be one to two orders of magnitude higher than for a fusion reactor.

Fracture toughness and low cycle fatigue tests were also carried out by these authors. At 0.4 dpa there was a sharp reduction in fracture toughness. For Heat 1 the reduction was between a factor of 3 and 5 for irradiated vs. unirradiated material, depending on the test temperature. For Heat 2 the reduction was not as large, ranging between about 1.7 and 2.5.

\section{Higher Dose Fission Reactor Irradiations}

Irradiation experiments were carried out in the Alloy Development for Irradiation Performance program of the fusion reactor materials program in the late 1970's and early 1980's. The irradiations took place in the EBR-II reactor. The first experiment accumulated a dose of about $2.8 \mathrm{dpa}$ at $450^{\circ} \mathrm{C}$ and was targeted to examine irradiation creep through the use of a stress relaxation technique [Nygren, 1979]. Ti-6Al-4V was included along with three other titanium alloys. A larger experiment was later carried out to examine additional properties of irradiated titanium alloys. Specimens were included to measure tensile, fatigue, crack growth, irradiation creep and swelling properties. Again, Ti-6Al-4V was included along with three other titanium alloys, two of those being the same as in the earlier experiment. The materials were irradiated at temperatures of 395,450 and $550{ }^{\circ} \mathrm{C}$ to doses up to 35 dpa [Peterson, 1982; Puigh, 1981; Puigh and Opperman, 1980]. The irradiation creep rates of the Ti-6Al-4V were higher than two of the other alloys by about two to seven times, depending upon the heat treatment given the Ti-6Al-4V alloy.

Swelling was measured by immersion density and was found to be about $1.5 \%$ or less at 450 
${ }^{\circ} \mathrm{C}$ for all alloys. At $550{ }^{\circ} \mathrm{C}$ the swelling of nearly $5 \%$ measured for Ti-6Al-4V was higher than for any of the other alloys. However, this amount was for the alloy in the beta annealed condition. The same alloy in other annealing conditions exhibited between 1.5 and $3.5 \%$ swelling at $550{ }^{\circ} \mathrm{C}$.

Fatigue crack propagation work on unirradiated material showed that the Ti-6Al-4V alloy in the mill annealed condition showed the fastest crack growth rate and the same alloy in the beta annealed condition showed the slowest crack growth rate of any of the alloys tested [Puigh and Ermi, 1981]. At low stress intensities the fracture surface of this alloy showed ductile features, while at higher stress intensities there were signs of more brittle failure including cleavage. The results were compared with corresponding results from testing the alloys HT-9, a ferritic/martensitic steel, and $20 \%$ cold-worked 316 stainless steel. The titanium alloys averaged a factor of three greater crack growth rates than these benchmark alloys, and crack propagation in the titanium alloys took place at lower stress intensity than for the stainless steel.

Some tensile testing was completed as part of this work. For the $550^{\circ} \mathrm{C}$ irradiation, matrix hardening was found with a corresponding increase in yield strength and reduction of ductility [Davis, et al., 1994]. Uniform and total elongations were found to range from 1 to 9 $\%$ for all the alloys. However, all of the $550^{\circ} \mathrm{C}$ alloys appear to have been corroded by a cleaning process [Puigh and Opperman, 1980; Puigh, 1981]. It is considered likely that the corrosion reduced the measured ductility in the tensile tests.

\section{Ion Irradiations}

A number of single- and dual-ion irradiations have been carried out over a wide range of doses and temperatures on several titanium alloys, including Ti-6Al-4V [Contact L. K. Mansur for a small collection of these references]. These studies usually covered shallow depths of order several $\mu \mathrm{m}$ or less. They generally aimed at examining swelling, dislocation densities, phase distributions and precipitation behavior, i.e., the microstructural aspects of radiation response. While these studies have contributed to the understanding of mechanisms, they could not directly address mechanical properties response to irradiation. Results are therefore considered to be of low direct relevance to evaluating the mechanical properties of the SNS target. 


\section{$\underline{\text { Summary }}$}

The radiation effects data available for Ti-6Al-4V and other titanium alloys are very sparse.

Helium and heavy-ion irradiation studies are available for a range of temperatures and doses. This work has been useful mainly for the characterization of microstructures and the understanding of mechanisms of radiation response. Its direct relevance to the SNS target is considered low.

Irradiations were carried out in a fast reactor, ranging up to $35 \mathrm{dpa}$ at temperatures from about 395 to $500{ }^{\circ} \mathrm{C}$. These temperatures are well above the operating temperature range of the SNS target, $\sim 100$ to $200^{\circ} \mathrm{C}$. Swelling and irradiation creep response of the alloys were characterized to a useful level and the mechanical testing was partially completed. However, problems with corrosion caused by a cleaning process made the measured ductilities unreliable. Considering the measured irradiation creep in these higher temperature irradiations and the design of the SNS target, it is not likely that irradiation creep would be a problem. Without further information, irradiation creep rates should be taken to be similar to those measured at $450{ }^{\circ} \mathrm{C}$. The point defect formation and absorption that lead to irradiation creep are athermal processes. (However, irradiation creep does depend on microstructure, which is temperature dependent.) Swelling was observed up to about $5 \%$ at 35 dpa at 550 ${ }^{\circ} \mathrm{C}$. At $450{ }^{\circ} \mathrm{C}$ the measured swelling was much lower. Based on theoretical and experimental knowledge that alloys exhibit a peak in swelling between 0.3 and $0.5 \mathrm{~T}_{\mathrm{m}}$ and on physical considerations [Mansur, 1987] such as lower point defect diffusivity and higher sink densities at lower temperatures, it is expected that swelling in Ti alloys at SNS target temperatures (about $0.2 \mathrm{~T}_{\mathrm{m}}$ ) would be negligible even at high doses.

Low dose data, $<1 \mathrm{dpa}$, at temperatures relevant to the SNS target are available from recent high energy proton irradiations and fission reactor neutron irradiations. The data indicate that Ti-6Al-4V increases in yield strength and loses ductility down to the range of several percent elongation, when subject to high energy proton or reactor neutron irradiation to low doses. The most relevant information is for doses well below $1 \mathrm{dpa}$. It is not known whether irradiations to higher doses at temperatures applicable to the SNS target will decrease uniform elongation and increase yield strength further, however, additional degradation with increasing dose is considered likely. In the non-irradiated condition Ti-6Al-4V is not particularly resistant to crack growth and fatigue with normal heat treatments that produce typical $\alpha+\beta$ microstructure. Incompatibilities between easy and difficult deformation directions in adjacent grains contribute to these weaknesses. However, such problems occur mainly for high plastic strains. If the material is not highly strained then it may perform adequately. 


\section{$\underline{\text { Recommendations }}$}

Titanium alloys should be examined further for application to the SNS target. The potential payoff is large but information applicable to the SNS target is largely non-existent. It is recommended that ORNL generate needed information using a graded approach.

1.) Examine Ti-6Al-4V and two additional titanium alloys for cavitation erosion behavior in mercury using ORNL's acoustic horn method and the Japan Atomic Energy Agency (JAEA) Magnetic Impact Test Machine (MIMTM). Compare the results with those for 316LN stainless steel. If the results are comparable or better, then go to the next step. If cavitation erosion performance is poor, then the alloy class probably would not be useful in the current SNS target design, which is expected to experience cavitation erosion. Note that it has not been demonstrated that the SNS target does indeed experience cavitation erosion.

2.) Carry out long term compatibility testing of the titanium alloys in mercury. If the results are satisfactory, then go to the next step.

3.) Perform irradiations of the titanium alloys to at least $5 \mathrm{dpa}$ in a fission reactor or spallation facility. Measure tensile, fatigue, and microstructural properties. If the response is satisfactory, then the alloys could be considered as candidates for future SNS targets.

\section{$\underline{\text { Acknowledgement }}$}

The SNS is sponsored by the Office of Science, US Department of Energy, under contract no. DE-AC05-00OR22725 with UT-Battelle, LLC.

\section{$\underline{\text { References }}$}

J. W. Davis, M. A. Ulrickson and R. A. Causey, "Use of titanium in fusion components", J. Nucl. Mater. 212-215 (1994) 813.

G. A. Greene and C. C. Finfrock, "Short-term solubility of eight alloys circulating in mercury at room temperature", AIChE Journal 49 (2003)1066.

A. Kohyama, K. Asano, N. Igata, "Neutron irradiation effects on electron beam welded titanium and Ti 6Al-4V", J. Nucl. Mater. 141-143 (1986) 987.

L. K. Mansur, "Mechanisms and Kinetics of Radiation Effects in Metals and Alloys," A chapter in the book, Kinetics of Non-Homogeneous Processes, edited by G. R. Freeman, Wiley-Interscience, New York 1987, pp. 377-463.

P. Marmy and T. Leguey, "Impact of irradiation on the tensile and fatigue properties of two titanium alloys”, J. Nucl. Mater. 296 (2004) 155.

R. E. Nygren, "Irradiation creep studies of titanium alloys", J. Nucl. Mater. 85\&86 (1979) 
861.

S. J. Pawel and L. K. Mansur, "Preliminary Evaluation of Cavitation-Erosion Resistance of Ti-Alloys in Mercury for the Spallation Neutron Source”, J. Nucl. Mater. (submitted).

D.T. Peterson, Swelling in Neutron Irradiated Titanium Alloys, Effects of Radiation on Materials: Eleventh Conference, ASTM STP 782, H. R. Brager and J. S. Perrin, Eds., American Society for Testing and Materials, 1982, pp. 260-274.

R.J. Puigh, "Corrosion of Titanium Alloy Specimens from AD-1 Experiment", Alloy Development for Irradiation Performance, DOE/ER-0045/6 (1981) pp. 106-109.

R.J. Puigh and A. M. Ermi, "Fatigue Crack Propagation in Selected Titanium Alloys", Alloy Development for Irradiation Performance, DOE/ER-0045/7 (1981) pp. 153-163.

R.J. Puigh and E.K. Opperman, "Examination of Titanium Alloy Specimens Irradiated in EBR-II", Alloy Development for Irradiation Performance, DOE/ER-0045/1 (1980) pp. 58-69.

B. S. Rodchenkov, et al., "Irradiation behaviour of titanium alloys for ITER blanket modules flexible attachment”, J. Nucl. Mater. 307-311 (2002) 421

B. S. Rodchenkov, et al., "Irradiation behaviour of Ti-4Al-2V (IIT-3B) for ITER blanket modules flexible attachment", J. Nucl. Mater. in press. 